\title{
The role of spontaneous general movement assessment in the neurological outcome of cerebral lesions in preterm infants
}

\author{
Importância da avaliação dos movimentos generalizados espontâneos \\ no prognóstico neurológico de recém-nascidos pré-termo
}

\author{
Juliana M. Garcia' ${ }^{1}$, José Luiz D. Gherpelli², Cléa R. Leone ${ }^{3}$
}

\begin{abstract}
Objective: To study the relationship among the quality, type, and trajectory of general movements in preterm infants and neonatal cranial ultrasonography findings and neurological outcome.

Method: Forty preterm newborn infants, with gestational ages under 35 weeks, had their general movements recorded through video-tape during the preterm, term (37th - 42nd postconceptional weeks of age) and post-term (49th - 56th postconceptional weeks of age) periods, and were prospectively followed up to one-year conceptional age.

Results: Our results showed that the quality of general movements, particularly in the post-term period $(p=0.009)$, were related with the presence of severe cerebral lesions in the neonatal cranial ultrasonography and the neurological outcome. While the presence of severe ultrasonography lesions was associated with an adverse neurological outcome $(p=0.01)$, the finding of normal general movements patterns was associated with a normal neurological outcome, with negative predictive values of $100 \%$, for the preterm, and $80 \%$, for both term and post-term periods.

Conclusions: When concurrently used, these evaluation methods may increase the specificity and sensitivity in detecting the group of preterm infants at high risk for neurological disturbances in longterm follow-up.
\end{abstract}

J Pediatr (Rio J). 2004;80(4):296-304: Low birth weight infant, intracranial hemorrhages, periventricular leukomalacia, motor activity, neurologic examination, ultrasonography, prognosis.

\section{Resumo}

Objetivo: Estudar a relação entre a qualidade, tipos e trajetória dos movimentos generalizados espontâneos em recém-nascidos prétermo com os achados da ultra-sonografia de crânio neonatal e com a evolução neurológica.

Método: 40 recém-nascidos pré-termo, com idades gestacionais $<35$ semanas, tiveram seus movimentos generalizados registrados através de videoteipe durante os períodos pré-termo, a termo $\left(37^{\mathrm{a}}-42^{\mathrm{a}}\right.$ semana de idade pós-concepcional) e pós-termo (49a-56a semana de idade pós-concepcional), e foram seguidos prospectivamente até um ano de idade pós-concepcional.

Resultados: Nossos resultados mostraram que a qualidade dos movimentos generalizados, particularmente no período pós-termo $(p=0,009)$, foram relacionados com a presença de lesões cerebrais detectadas à ultra-sonografia e com a evolução neurológica. Enquanto a presença de lesões ultra-sonográficas graves foi associada à evolução neurológica desfavorável $(p=0,01)$, o achado de padrões de movimentos generalizados espontâneos normais foi associado à normalidade neurológica no seguimento, com valores preditivos negativos de $100 \%$, para o período pré-termo, e $80 \%$ para ambos os períodos a termo e póstermo.

Conclusões: Quando usados conjuntamente, esses métodos podem aumentar a especificidade e a sensibilidade na deteç̧ão de um grupo de recém-nascidos pré-termo de alto risco para seqüelas neurológicas, no seguimento a longo prazo.

J Pediatr (Rio J). 2004;80(4):296-304: Recém-nacido de baixo peso, hemorragia intracraniana, leucomalácia periventricular, atividade motora, exame neurológico, ultra-sonografia, prognóstico.

\section{Introduction}

In spite of the improvement in both prenatal assistance and neonatal intensive care, which have considerably decreased neonatal mortality, preterm newborns (PTNB)

1. Physical therapist, Department of Neurology and Pediatrics, Hospital das Clínicas, School of Medicine, Universidade de São Paulo (USP), São Paulo, SP, Brazil.

2. $\mathrm{MD}, \mathrm{PhD}$, Pediatric neurologist, Department of Neurology and Pediatrics, Hospital das Clínicas, School of Medicine (USP), São Paulo, SP, Brazil.

3. MD, PhD, Neonatologist, Department of Neurology and Pediatrics, Hospital das Clínicas, School of Medicine (USP), São Paulo, SP, Brazil.

Manuscript received Oct 08 2003, accepted for publication Jan 092004.

are at a high risk for central nervous system dysfunctions related to cerebral insults that occur in the prenatal or perinatal period. ${ }^{1}$

The major neurological disorders commonly related to perinatal brain injury in the PTNB are the diplegic or hemiplegic forms of cerebral palsies - often accompanied by cognitive disorders. The neuropathology most often related to these motor disorders is periventricular hemorrhagic infarction - which is considered one of the complications of periventricular hemorrhage - and periventricular leukomalacia. ${ }^{2}$ 
Serial cranial ultrasonography (US) is the procedure of choice for the diagnosis of brain lesions early in the neonatal period and several brain sonographic findings have been related to neurological outcome. ${ }^{3}$ Mortality and neurological outcome are directly related to damage to the periventricular white matter, which is found in the sick preterm infant. 4

Although several studies relate the severe abnormalities detected by neonatal cranial US, such as multicystic periventricular leukomalacia, periventricular hemorrhage, and hydrocephalus, to neurological disorders observed in the long-term follow-up, ${ }^{4-7}$ minor cranial sonographic findings seem to have a doubtful prognostic value. ${ }^{8-10}$

Clinical neurological evaluation is widely used for the diagnosis of brain lesions in the neonatal period. Although clinical evaluation is considered useful for detecting neurological abnormalities in the acute phase of the brain insult in full-term infants, the large number of false positives and false negatives observed in the long-term neurological follow-up, and the difficulties in devising appropriate clinical methods for the preterm infant, created an almost total dependence on imaging studies in the neurological evaluation of preterm babies. ${ }^{3}$

Spontaneous general movements (GM) are present from the fetal period to approximately 20 weeks postnatally. ${ }^{11-13}$ They are complex, often involving the whole body, frequent, present either during wakefulness or sleep, and exhibit pattern changes, as the infant grows older. Their presence, quality and intensity may be a marker of the infant's central nervous system functional integrity, and several abnormality patterns in their expression were related to an adverse neurological outcome, suggesting that they may be a useful tool for indicating perinatal brain damage. ${ }^{14}$ In this context, Prechtl's method for the qualitative assessment of general movements (GM) has been used as a diagnostic tool for early detection of brain dysfunction. ${ }^{15}$ Observing a video recording of an infant's GM allows the trained observer to assess his motor activity, yielding a high interscorer agreement. ${ }^{16}$

Although this assessment method is considered to be useful in the context of predicting neurologic sequelae in preterm infants it is not widely used, perhaps because only a few researchers outside Precht's original circle have been trained so far, and almost all published data come from the original group that developed the evaluation method. Therefore it is important to validate the method in other populations. Ours is the first study to use the method outside Europe, to the best of our knowledge.

The present study was designed to: 1) study the relationship between the qualitative characteristics of the GM in the preterm, full-term and post-term periods, and both the results of the cranial US examinations in the neonatal period, and the neurological outcome; 2) study the relationship between the different types of GM abnormalities in the preterm, full-term and post-term periods and both the results of the cranial US examinations in the neonatal period, and the neurological outcome; 3 ) study the relationship between the GM trajectory and neurological outcome.

\section{Method}

This study was carried out at the Neonatal Unit and Developmental Neurology Clinic of the Hospital das Clínicas, School of Medicine of Universidade de São Paulo. The study protocol was previously approved by the Ethics Committee of our institution and a signed informed consent was obtained from the parents.

Infants were selected based on their mothers' willingness to participate in the study. Infants included were chosen consecutively among those born below 35 weeks of gestational age (GA), between January and November 2000.

Exclusion criteria were the presence of major congenital malformations, congenital infections, osteoarticular disorders, or the use of CNS depressant drugs.

All newborns underwent cranial US examination within the first 10 days of life, or as soon as possible, which was repeated every 1 or 2 weeks, if abnormal. Periventricular hemorrhage $(\mathrm{PVH})$, whenever present, was classified according to the criteria proposed by Papile et al. ${ }^{17}$ Periventricular leukomalacia was diagnosed when cystic hypoechoic lesions developed in the periventricular white matter in serial sonographic examinations.

Spontaneous GM recordings were performed after the infant was free of mechanical devices that could affect the expression of free spontaneous movements. All infants had their GM recorded on a weekly basis up to hospital discharge, except those who had the recordings interrupted due to the deterioration of their clinical condition. After hospital discharge, a return visit was scheduled between the 37th and 42nd postconceptional weeks (term), and another one between the 49 th and 56 th postconceptional weeks (post-term), for the video recordings.

The recording time varied according to the infant's age; 20 minutes, in the preterm period, and 10 minutes, in the term and post-term period. This time period was considered enough to record the infants' spontaneous GM as determined by a pilot study carried out 2 months before the beginning of the study.

The recordings were performed between feedings, preferably during active wakefulness, or during sleep (mainly in the preterm period), but always when spontaneous movements were present. If periods of prolonged fussing or crying were present, the recording was postponed.

The infants were placed in the supine position, free of restricting devices, with their beds elevated at an angle of 30 degrees. They wore either diapers or short clothes, which did not interfere with their freedom of movement, or with the visualization of arms and legs. No kind of manipulation was allowed during the recordings.

A Panasonic NV-VZ 105 portable video camera attached to a Velbon DF 60 tripod was used to record the babies on JVC VHS 30 compact videocassettes. The video camera was placed either over the baby, central or lateral to the baby's body, so that he would fit on the screen from the shortest possible distance. 
The qualitative evaluation of the GM was carried out according to Prechtl's method for the assessment of spontaneous movements. ${ }^{16}$ Each recording period was analyzed by one of the authors (JMG), who was previously trained and certified in the method, and three GM instances on the tape were selected and the exact time when each of the selected time periods began and ended were recorded. The author in charge of the GM analysis was not aware of the cranial US and of the neurological evaluation results.

Based on the GM patterns for each age period the observer classified the spontaneous movements of the three selected time periods as either normal or abnormal. The abnormalities observed were classified according to the same assessment method.

During the preterm period, the normal motor patterns involve the whole body, displaying a changeable sequence of limbs, trunk, and head movements. These motor patterns may last just a few seconds or up to several minutes. They wax and wane in intensity, force, and speed, and have a gradual beginning and end. The majority of sequences of extension and flexion movements of arms and legs are complex, with superimposed rotations, and often slight changes in the direction of the movement.

In the term period up to the 6th or 9th post-term week, the motor patterns are characterized by small amplitude and slow to moderate speed. However, wide and fast extensor movements may occur, particularly those of the upper limbs. These movements display an elliptic form, and are called "writhing movements."

From the preterm period up to the 9th post-term week, abnormal motor patterns are classified into the following categories:

- poor repertoire (PR): motor patterns whose sequence becomes monotonous and whose complexity is different from normal;

- cramped synchronized (CS): the movements appear rigid and lack the normal smooth and fluent character, without the fluency, elegance and complexity of normal motor patterns. The limbs and trunk muscles contract and relax simultaneously;

- chaotic ( $\mathrm{CH})$ : movements of great amplitude that are deprived of the fluency and elegance of normal motor patterns.

Around the 6th and 9th post-term weeks, the motor patterns start changing their characteristics. Limbs, trunk, and head movements display small amplitude, moderate speed, and variable acceleration and are continuously present when the baby is awake, except during visual fixation. Prechtl called them "fidgety movements" (F).

The motor pattern abnormalities mentioned above may be divided into two categories:

a) Absent (Fab): absence of fidgety movements.

b) Abnormal (Fanl): moderate or severe increase of both amplitude and speed, and loss of continuity of the fidgety movements.
The results of one of the GM recordings on the 34th, 40th, and 52nd postconceptional weeks were used as representative of each time period for the analysis.

The analysis of the GM trajectory was performed based on the results of all the recordings obtained during the study period from the same infant. Trajectories that started with normal or abnormal GM and ended up normal were classified as "normal end trajectory", and trajectories that started out normal or abnormal and finished with abnormal GM, were classified as "abnormal end trajectory".

After discharge from the neonatal unit, the infants were followed up to at least one year of postconceptional age, at the outpatient clinic of the Developmental Neurology unit, by one of the authors. The follow-up visits were scheduled every 3 months. Neurological examination and developmental assessment, based on the Denver Developmental Screening Test, were performed in each visit, without knowledge of the cranial US and GM analysis results.

Neurological outcome was considered abnormal when the neurological examination revealed a definite focal neurological abnormality (ataxia, hemiparesis, paraparesis, dystonia, hypotonia), and when the developmental profile was abnormal. Infants were considered suspected cases when the neurological examination showed only mild abnormalities (hyperactive reflexes, slight tonus abnormalities, hand incoordination) and when the developmental test showed abnormal results in at least two items. For statistical purposes the abnormal and suspect infants were grouped together in the abnormal outcome group. A normal outcome was considered when both neurological examination and developmental testing were normal for the corrected age.

Statistical analysis was performed using the McNemar test in order to study the concordance between the quality and the abnormality types of the GM observed in the neonatal cranial ultrasonographic findings, and the neurological outcome for each age period.

Fisher's exact test was used to study the relationship between the GM trajectory and the neurological outcome.

Rejection level for the null hypothesis was $p=0.05$.

Sensitivity, specificity, positive (PPV) and negative (NPV) predictive values were calculated for the variables studied.

\section{Results}

One hundred and forty-two children were born with GA $<35$ weeks between January and November 2000. Table 1 shows the characteristics of the studied population. Forty PTNB were selected, with GA varying between 26 and 34 weeks (mean $=31$ ), birth weights of 630 to 1,530 $\mathrm{g}$ (mean =1,100), and mean Apgar scores of 5, 7, and 9, in the $1 \mathrm{st}, 5$ th, and 10 th minutes, respectively. There were 21 boys, and 19 girls, and 26 infants were classified as small for gestational age. 
Table 1 - General characteristics of the studied population

\begin{tabular}{|c|c|c|c|c|c|c|c|c|c|}
\hline Case & $\begin{array}{c}\text { GA } \\
\text { (weeks) }\end{array}$ & $\begin{array}{c}\text { BW } \\
\text { (grams) }\end{array}$ & Sex & $\begin{array}{c}\text { SGA/ } \\
\text { AGA }\end{array}$ & $\begin{array}{l}\text { 1' Apgar } \\
\text { score }\end{array}$ & $\begin{array}{l}\text { 5' Apgar } \\
\text { score }\end{array}$ & $\begin{array}{l}\text { 10' Apgar } \\
\text { score }\end{array}$ & US & NO \\
\hline 1 & $303 / 7$ & 880 & $\mathrm{~F}$ & SGA & 6 & 8 & 9 & PVH grade I & NL \\
\hline 2 & $291 / 7$ & 760 & $\mathrm{~F}$ & SGA & 4 & 7 & 9 & PVH grade III & - \\
\hline 3 & $276 / 7$ & 1,000 & $M$ & AGA & 0 & 3 & 7 & PVL & suspect \\
\hline 4 & 29 & 1,126 & $\mathrm{~F}$ & AGA & 9 & 9 & 10 & PVL & - \\
\hline 5 & $303 / 7$ & 1,310 & $\mathrm{~F}$ & SGA & 3 & 7 & 9 & $\mathrm{NL}$ & NL \\
\hline 6 & $331 / 7$ & 1,380 & $\mathrm{~F}$ & AGA & 8 & 9 & 10 & NL & NL \\
\hline 7 & $323 / 7$ & 1,060 & $M$ & SGA & 9 & 10 & 10 & NL & NL \\
\hline 8 & $291 / 7$ & 960 & $\mathrm{~F}$ & SGA & 7 & 9 & 10 & $\mathrm{NL}$ & NL \\
\hline 9 & $275 / 7$ & 890 & M & AGA & 2 & 6 & 8 & PVH grade III & $\mathrm{NL}$ \\
\hline 10 & $323 / 7$ & 930 & $M$ & SGA & 6 & 7 & 8 & LV asymmetry & suspect \\
\hline 11 & $304 / 7$ & 1,120 & $\mathrm{~F}$ & SGA & 8 & 9 & 10 & $\mathrm{NL}$ & - \\
\hline 12 & $284 / 7$ & 870 & $M$ & AGA & 7 & 8 & 8 & $\mathrm{NL}$ & suspect \\
\hline 13 & $302 / 7$ & 1,430 & $M$ & AGA & 7 & 8 & 9 & PVH grade III & - \\
\hline 14 & $285 / 7$ & 1,000 & M & AGA & 7 & 8 & 9 & PVH grade II & NL \\
\hline 15 & $314 / 7$ & 1,400 & $\mathrm{~F}$ & AGA & 8 & 8 & 9 & $\mathrm{NL}$ & $\mathrm{NL}$ \\
\hline 16 & $262 / 7$ & 910 & $M$ & AGA & 1 & 7 & 8 & PVL & ANL \\
\hline 17 & $265 / 7$ & 1,080 & $\mathrm{~F}$ & AGA & 1 & 5 & 9 & PVH grade III & ANL \\
\hline 18 & $314 / 7$ & 700 & $\mathrm{~F}$ & SGA & 4 & 9 & 10 & $\mathrm{NL}$ & - \\
\hline 19 & $303 / 7$ & 1,130 & $\mathrm{~F}$ & SGA & 3 & 7 & 9 & $\mathrm{NL}$ & $\mathrm{NL}$ \\
\hline 20 & $304 / 7$ & 950 & $\mathrm{~F}$ & SGA & 7 & 10 & 10 & Choroid plexus cyst & Suspect \\
\hline 21 & $323 / 7$ & 1,490 & $M$ & AGA & 8 & 9 & 10 & $\mathrm{NL}$ & - \\
\hline 22 & $303 / 7$ & 1,090 & M & SGA & 3 & 7 & 8 & $\mathrm{NL}$ & NL \\
\hline 23 & $302 / 7$ & 1,140 & $\mathrm{~F}$ & SGA & 2 & 9 & 9 & PVH grade III & NL \\
\hline 24 & $315 / 7$ & 1,240 & $\mathrm{~F}$ & AGA & 8 & 9 & 9 & $\mathrm{NL}$ & NL \\
\hline 25 & $333 / 7$ & 1,760 & $M$ & AGA & 7 & 8 & 9 & NL & - \\
\hline 26 & $311 / 7$ & 1,140 & M & SGA & 8 & 9 & 9 & NL & - \\
\hline 27 & $333 / 7$ & 1,090 & M & SGA & 1 & 8 & 9 & NL & NL \\
\hline 28 & $304 / 7$ & 630 & $M$ & SGA & 2 & 6 & 8 & NL & - \\
\hline 29 & $345 / 7$ & 1,520 & $\mathrm{~F}$ & SGA & 9 & 9 & 9 & NL & - \\
\hline 30 & $344 / 7$ & 1,530 & $\mathrm{~F}$ & SGA & 1 & 5 & 9 & $\mathrm{NL}$ & - \\
\hline 31 & $332 / 7$ & 1,130 & $\mathrm{~F}$ & SGA & 4 & 10 & 10 & $\begin{array}{l}\text { Periventricular } \\
\text { calcifications }\end{array}$ & Suspect \\
\hline 32 & $331 / 7$ & 860 & M & SGA & 8 & 9 & 10 & NL & $\mathrm{NL}$ \\
\hline 33 & $276 / 7$ & 810 & $\mathrm{~F}$ & SGA & 1 & 1 & 4 & NL & ANL \\
\hline 34 & $285 / 7$ & 720 & $\mathrm{~F}$ & SGA & 1 & 8 & 8 & $\mathrm{NL}$ & Suspect \\
\hline 35 & $276 / 7$ & 820 & $\mathrm{~F}$ & SGA & 1 & 3 & 7 & PVH grade II & - \\
\hline 36 & $291 / 7$ & 930 & $\mathrm{~F}$ & SGA & 1 & 1 & 4 & $\mathrm{NL}$ & - \\
\hline 37 & $275 / 7$ & 1,100 & $M$ & AGA & 4 & 7 & 8 & NL & NL \\
\hline 38 & $273 / 7$ & 680 & M & SGA & 3 & 8 & 10 & $\mathrm{NL}$ & NL \\
\hline 39 & $314 / 7$ & 1,330 & M & SGA & 8 & 9 & 9 & PVH grade III & - \\
\hline 40 & 30 & 680 & M & SGA & 6 & 7 & 8 & PVL & ANL \\
\hline
\end{tabular}

$\mathrm{AGA}=$ appropriate for gestational age $; \mathrm{ANL}=$ abnormal $; \mathrm{BW}=$ birth weight $\mathrm{US}=$ cranial ultrasonography $\mathrm{F}=$ female $\mathrm{GA}=$ gestational age $\mathrm{LV}=$ lateral ventricle $\mathrm{M}=$ male $; \mathrm{NL}=$ normal; $\mathrm{NO}=$ neurological outcome; $\mathrm{PVH}=$ periventricular hemorrhage; $\mathrm{PVL}=$ periventricular leukomalacia; $\mathrm{SGA}=\mathrm{small}$ for gestational age .

Cranial US examinations were abnormal in $15(37.5 \%)$ infants. PVH was present in nine (22.5\%) infants (one, grade I, two, grade II, and six grade III). Four infants had periventricular leukomalacia, one infant had an asymmetrical non-hypertensive ventricular dilatation, and one, choroid plexus cysts. Those infants that had PVH grade I, or II, and choroid plexus cyst, were grouped together with those with a normal sonographic examination for the sake of statistical analysis, as these abnormalities have a similar neurological prognosis to those observed in infants with a normal cranial ultrasound.
The infants' mean age at the beginning of the video recordings was 25 days, and the mean number of recordings for each infant was six. Seven infants had no recordings performed in the preterm period, two infants, in the term period, and 14 infants, in the post-term period.

Of the 40 infants initially included in the study, 26 were followed up to a mean of 14 months conceptional age (12 to 19 months). Eight infants were lost to follow-up, three infants were followed up to 3 months, and three, up to 9 months conceptional age. 
Sixteen infants $(61.5 \%)$, out of the 26 infants followed up to at least 1 year corrected age, had a normal neurological outcome. Five infants were definitely abnormal, all with motor disorders and developmental delay (two hemiplegic, one ataxic, one diplegic, and one quadriplegic). The other five had mild findings; three infants were developmentally delayed in the social and motor-adaptive areas, one had a mild increase in the leg muscle tone and hyperactive reflexes without major functional involvement, and one infant had leg rotation and foot pronation during walking, and trunk-leg incoordination when assuming the sitting position.

\section{GM and neonatal cranial US examinations}

Table 2 shows the results of the analysis of the GM recordings in the preterm, term, and post-term periods and the results of the neonatal cranial US examinations. We observed a statistically significant and positive relationship only in the post-term period $(p=0.009)$. Although no significant relationship was observed in the preterm or term periods, we noticed that normal GM were often present in infants with normal US examinations (PPV of $85 \%$ in the preterm period, $82 \%$ in the term, and $86 \%$ in the postterm), while abnormal GM were observed in infants with either normal or abnormal ultrasounds (PPV of $25 \%, 41 \%$, and $67 \%$, respectively), as shown in Table 3 . Most infants with abnormal US had abnormal GM, with sensitivity values of $71 \%, 75 \%$, and $80 \%$, in the preterm, term, and postterm periods, respectively, and infants with normal cranial US sometimes had abnormal GM, with specificity of $42 \%$, $52 \%$, and $75 \%$, in the preterm, term, and post-term periods, respectively (Table 3 ).

These results show that sensitivity and NPV were high in all age periods, while specificity and PPV were high only in the post-term period.

Table 2 - Quality of general movements, types of abnormalities during preterm, term and post-term periods, and neonatal cranial ultrasonography

\begin{tabular}{|c|c|c|c|c|c|}
\hline Age period & $\begin{array}{l}\text { Quality of } \\
\text { general movements }\end{array}$ & $\begin{array}{c}\text { Cranial ul } \\
\text { Normal }\end{array}$ & $\begin{array}{c}\text { sonography } \\
\text { Abnormal }\end{array}$ & Total & $\mathbf{p}$ \\
\hline \multirow[t]{5}{*}{ Preterm } & Normal & 11 & 2 & 13 & \\
\hline & Abnormal & & & 20 & \\
\hline & PR & 10 & 1 & & 0.41 \\
\hline & CS & 5 & 4 & & \\
\hline & Total & 26 & 7 & 33 & \\
\hline \multirow[t]{5}{*}{ Full-term } & Normal & 14 & 3 & 17 & \\
\hline & Abnormal & & & 22 & \\
\hline & PR & 7 & 2 & & 0.18 \\
\hline & CS & 6 & 7 & & \\
\hline & Total & 27 & 12 & 39 & \\
\hline \multirow[t]{5}{*}{ Post-term } & Normal & 12 & 2 & 14 & \\
\hline & Abnormal & & & 12 & \\
\hline & Fabn & 2 & 1 & & $0.009 *$ \\
\hline & Fabs & 2 & 7 & & \\
\hline & Total & 16 & 10 & 26 & \\
\hline
\end{tabular}

$\mathrm{CS}=$ cramped synchronized; Fabn = abnormal fidgety movements $;$ Fabs = absence of fidgety movements; $P R=$ poor repertoire . ${ }^{*}$ = significant Fisher's exact test.

Table 3 - $\quad$ Sensitivity, specificity and positive and negative predictive values

\begin{tabular}{|c|c|c|c|c|c|}
\hline \multirow[b]{2}{*}{ Type of assessment } & \multirow[b]{2}{*}{ Age period } & \multirow[b]{2}{*}{$\begin{array}{c}\text { Sensitivity } \\
\%\end{array}$} & \multirow[b]{2}{*}{$\begin{array}{c}\text { Specificity } \\
\%\end{array}$} & \multicolumn{2}{|c|}{ Predictive value } \\
\hline & & & & $\begin{array}{l}\text { Positive } \\
\%\end{array}$ & $\begin{array}{c}\text { Negative } \\
\%\end{array}$ \\
\hline GM quality $X$ & preterm & 71 & 42 & 25 & 85 \\
\hline \multirow[t]{2}{*}{ Cranial ultrasonography } & term & 75 & 52 & 41 & 82 \\
\hline & post-term & 80 & 75 & 67 & 86 \\
\hline GM quality $X$ & preterm & 100 & 44 & 36 & 100 \\
\hline \multirow[t]{2}{*}{ Neurological outcome } & term & 78 & 50 & 47 & 80 \\
\hline & post-term & 75 & 67 & 60 & 80 \\
\hline $\begin{array}{l}\text { Qualitative trajectory of GM x } \\
\text { Neurological outcome }\end{array}$ & & 86 & 53 & 40 & 91 \\
\hline Cranial ultrasonography $x$ & & 60 & 87 & 75 & 78 \\
\hline Neurological outcome & & & & & \\
\hline
\end{tabular}




\section{Types of GM and neonatal US examinations}

A positive relationship was observed between the abnormal types of GM and the cranial US in all age periods, with a higher concordance in the post-term period $(75 \%)$, as compared with the term (64\%) and preterm (70\%) periods. In the preterm period, most infants with abnormal GM and normal cranial US examinations had a poor repertoire of GM, while in the term and post-term periods, we could not find a particular type of GM abnormality associated with normal US examinations. In the preterm and term periods, the GM of the cramp synchronized type were mostly associated with abnormal US findings, and in the post-term period, the absence of fidgety movements was often found in infants with an abnormal US examination (Table 2 ).

\section{GM and neurological outcome}

We found a statistically significant and positive relationship between GM quality and neurological outcome in the follow-up to at least one-year conceptional age in the term and post-term periods. The concordance was higher in the post-term ( $70 \%$ ) compared with the term (60\%) period (Table 4). Although the relationship was not observed in the preterm period, a high trend was noticed between the occurrence of normal GM and normal neurological outcome in all age periods (NPV of $100 \%$ in the preterm, and $80 \%$ in both term and post-term periods). On the other hand, abnormal neurological outcome was associated with either normal or abnormal GM in all age periods (PPV of $36 \%, 47 \%$, and $60 \%$, respectively), as shown in Table 3 .
Most infants with abnormal neurological outcome had abnormal GM in all age periods (sensitivity of $100 \%$, in the preterm, $78 \%$, in term, and $75 \%$, in post-term period), while the percentage of infants with normal GM among those with a normal neurological outcome increased with age (specificity of $44 \%$, in the preterm, $50 \%$, in term, and $67 \%$, in post-term period), as can be seen in Tables 3 and 4.

\section{Types of GM abnormalities and neurological outcome}

We found a statistically significant relationship between the type of GM abnormality and the neurological outcome in the three age periods studied, although the concordances were close to the discordance values $(50 \%, 53 \%$, and $50 \%$, for concordance, and $50 \%, 47 \%$, and $50 \%$, for discordance, in preterm, term, and post-term periods, respectively). None of the GM abnormal types was particularly related to the neurological outcome (Table 4).

\section{GM trajectory and neurological outcome}

There was no statistically significant relationship between GM trajectory and the neurological outcome ( $p$ $=0.09$ ), as can be seen in Table 5. Notwithstanding this finding, the majority of the infants with a "normal end trajectory" had a normal neurological outcome in the follow-up (NPV $=91 \%$, and among the infants with an "abnormal end trajectory", several had a normal neurological outcome (PPV $=40 \%)$, as shown in Table 3.

Table 4 - Quality of general movements, types of abnormalities during preterm, term and post-term periods, and the neurological outcome at one year of post-conceptional age

\begin{tabular}{|c|c|c|c|c|c|}
\hline Age period & $\begin{array}{l}\text { Quality of general } \\
\text { movements }\end{array}$ & $\begin{array}{l}\text { Neurolos } \\
\text { Normal }\end{array}$ & $\begin{array}{l}\text { Al outcome } \\
\text { Abnormal }\end{array}$ & Total & $\mathbf{p}$ \\
\hline \multirow[t]{4}{*}{ Preterm } & $\begin{array}{l}\text { Normal } \\
\text { Abnormal }\end{array}$ & 7 & 0 & $\begin{array}{c}7 \\
14\end{array}$ & \\
\hline & PR & 4 & 2 & & $p=0.09$ \\
\hline & CS & 5 & 3 & & \\
\hline & Total & 16 & 5 & 21 & \\
\hline \multirow[t]{4}{*}{ Full-term } & $\begin{array}{l}\text { Normal } \\
\text { Abnormal }\end{array}$ & 8 & 2 & $\begin{array}{l}10 \\
15\end{array}$ & \\
\hline & PR & 4 & 3 & & $p=0.17$ \\
\hline & $\mathrm{CS}$ & 4 & 4 & & \\
\hline & Total & 16 & 9 & 25 & \\
\hline \multirow[t]{5}{*}{ Post-term } & Normal & 8 & 2 & 10 & \\
\hline & Abnormal & & & 10 & \\
\hline & Fabn & 1 & 2 & & \\
\hline & Fabs & 3 & 4 & & $p=0.08$ \\
\hline & Total & 12 & 8 & 20 & \\
\hline
\end{tabular}

$\mathrm{CS}=$ cramped synchronized; Fabn = abnormal fidgety movements; Fabs = absence of fidgety movements; PR = poor repertoire. Fisher's exact test. 
Table 5 - Developmental trajectory of the quality of general movements and the outcome at one year of postconceptional age

\begin{tabular}{lccrrr}
\hline $\begin{array}{l}\text { Developmental } \\
\text { trajectory of the } \\
\text { quality of general } \\
\text { movements }\end{array}$ & \multicolumn{2}{c}{$\begin{array}{c}\text { Outcome } \\
\text { at one year }\end{array}$} & & & \\
\cline { 2 - 3 } & Normal & Abnormal & Total & p \\
\hline Normal end & 10 & 1 & 11 & \\
Abnormal end & 9 & 6 & 15 & $p=0.09$ \\
Total & 19 & 7 & 26 & \\
\hline
\end{tabular}

Fisher's exact test.

Sensitivity of "normal end trajectory" for normal neurological outcome was high $(86 \%)$, and specificity of "abnormal end trajectory" for abnormal neurological outcome was low $(53 \%)$, as can be observed in Table 3.

\section{Neonatal US examination and neurological outcome}

Comparing the neurological outcome at follow-up with the results of cranial US examinations performed in the neonatal period, we found a positive and significant relationship between them $(p=0.01)$, as shown in Table 6 .

Table 6 - Neonatal cranial ultrasonography and outcome at one year of post-conceptional age

\begin{tabular}{lccccc}
\hline $\begin{array}{l}\text { Neonatal cranial } \\
\text { ultrasonography }\end{array}$ & \multicolumn{2}{c}{ Outcome at one year } & & \\
\cline { 2 - 3 } & Normal & Abnormal & Total & $\mathbf{p}$ \\
\hline Normal & 14 & 4 & 18 & \\
Abnormal & 2 & 6 & 8 & $\mathrm{p}=0.01^{*}$ \\
Total & 16 & 10 & 26 & \\
\hline
\end{tabular}

* = significant

Fisher's exact test.

The majority of infants that had neonatal US examination classified as normal were neurologically normal at follow-up (specificity of $87 \%$ ), and several infants with normal neurological outcome had a neonatal cranial US considered as normal (of $60 \%$ ). Most infants with a normal US had a normal neurological outcome (NPV $=78 \%$ ), and among those with an abnormal US examination, the neurological outcome was often abnormal (PPV $=75 \%$ ), as shown in Tables 3 and 6 .

\section{Discussion}

Our results showed that the quality of GM observed in the post-term period in preterm infants was related to brain lesions, such as severe PVH and periventricular leukomalacia, detected through neonatal cranial US examinations. The same relationship was observed in other studies $14,18,19$ that used the same GM evaluation method, and reported a relationship between the quality of GM, particularly in the post-term period, and severe neonatal US abnormalities in PTNB. Although we have not observed this relationship in the preterm and term age periods, the GM evaluation showed a high sensitivity in all age periods, especially in the post-term $(80 \%)$, with a high NPV $(86 \%)$. These findings suggest that the method is useful to detect infants that are free of major cranial US abnormalities in the neonatal period, and shows that infants who have a major brain lesion in the neonatal US examinations often have abnormal GM. The results of our study showed that specificity and PPV were higher in the post-term period, suggesting that, around three months of corrected age, most infants that had a normal cranial US in the neonatal period will exhibit normal GM quality, and those with abnormal GM have a high rate of severe abnormal US findings in the neonatal period.

Bos et al. ${ }^{20}$ studied 19 SGA preterm infants (GA between 26-35 weeks) and compared the quality of the GM with 14 appropriate for gestational age preterm newborns. They found that a transitory dysfunction of the GM without a correspondent abnormality in the cranial US examination might be present in SGA babies. Most infants with poor repertoire of GM had a normal cranial US in our study. The large number of SGA infants in our study may explain the high percentage of infants with poor repertoire of GM, mainly in the preterm period.

Prechtl et al. ${ }^{21}$ compared the qualitative aspects of GM in 130 infants (GA between 26 and 41 weeks) with the results of neonatal cranial US examinations, and observed sensitivity levels of $80 \%$, and specificity of $83 \%$ in GM evaluation in the post-term age period. No mention was made concerning the predictive values, but they found a relationship between the presence of abnormal GM and abnormal neonatal cranial US examinations.

We could not find an association between the quality of GM observed in the preterm, term and post-term periods, and neurological outcome. Our results are in disagreement with other studies, $14,18,19,21-24$ which found a relationship between the quality of spontaneous GM, mainly in the postterm period, and neurological outcome, although the followup period varied between the studies (around 2 years of age). Several studies showed a relationship between absence of fidgety movements and abnormal neurological outcome, in preterm and term NB infants, ${ }^{19,24}$ and in SGA PTNB. ${ }^{25}$

Bos et al. ${ }^{25}$ observed a higher concordance between the qualities of the GM in the post-term compared with the preterm and term periods, and neurological outcome at 2 years of age. The relationship between the quality of fidgety movements and neurological outcome was observed in other studies.16,19,24,26 Our study showed that, in all periods evaluated, the abnormal GM were related to neurological abnormalities in the follow-up. On the other hand, several infants with a normal neurological outcome had abnormal GM, mainly in the preterm and term periods. The sensitivity of the qualitative GM evaluations was high in all age periods (mean $=84 \%$ ), while specificity was low in 
the preterm and term periods, increasing slightly in the post-term period. These findings were also reported by Einspieler et al., ${ }^{16}$ who reviewed six different studies that evaluated the quality of GM in PTNB and found a high sensitivity in all age groups ( mean $=94 \%$ ), with a specificity that was age-dependent, being low in the preterm period, and gradually increasing with conceptional age.

Our study showed that a high proportion of infants with normal GM in all age periods had a normal neurological outcome (NPV of $100 \%$, in preterm, and of $80 \%$, in term and post-term periods), while several infants with abnormal GM, particularly in the preterm and term periods, had a normal neurological outcome at follow-up (PPV of $36 \%$, $47 \%$, and $60 \%$, in preterm, term, and post-term periods, respectively). No study reported the NPV, or PPV of GM assessment and neurological outcome.

Ferrari et al. ${ }^{14}$ studied 29 PTNB with abnormal and 14 with normal neonatal cranial US examinations, showing that the NPV was superior to the PPV in predicting the neurological outcome at follow-up at 2 years of age. Hadders-Algra \& Groothuis, ${ }^{24}$ studying the neurological outcome at 4-9 years of age in 52 newborns, 18 preterm, 28 healthy term and six term infants with hypoxic-ischemic encephalopathy, found a higher PPV for long-term neurological outcome in the post-term period. The large number of infants with abnormal GM that had a normal neurological outcome found in our study may be related to one or more of the following factors: the large proportion of SGA, presence of a transitory brain dysfunction in the neonatal period, or the short followup, which was unable to diagnose subtle neurological dysfunctions that might be observed later, at school age.

We found no relationship between the qualitative trajectory of the GM and neurological outcome. Our results differ from those of Bos et al. 20,25 who studied preterm infants and showed that the longitudinal assessment of GM quality was related to neurological outcome. On the other hand, we found a high sensitivity ( $86 \%$ ) and NPV (91\%) for the "normal end trajectory" regarding neurological outcome.

Several studies reported a strong relationship between severe neonatal cranial US abnormalities, such as periventricular hemorrhagic infarction, periventricular hemorrhage with hydrocephalus, and periventricular leukomalacia, with neurological abnormalities in the followup. 4-7,27-30 A normal cranial US, or presence of grade I or II PVH, were associated with a better neurological prognosis, although some of these infants exhibited neurological abnormalities in the follow-up. $3,8,10,30$ These findings are in agreement with our results.

$\mathrm{Ng} \&$ Dear, 31 in a meta-analysis, found values of $66 \%$ for the sensitivity, and $60 \%$, for specificity of the neonatal cranial US in predicting the neurological outcome. The NPV was $88 \%$, and PPV, $36 \%$. We found higher values for specificity $(87 \%)$ and PPV $(75 \%)$, and similar values for sensitivity $(60 \%)$ and NPV (78\%).

We conclude that both neonatal cranial US and Prechtl's method for GM assessment are useful in predicting the neurological outcome of PTNB. Cranial US examination shows high specificity, while GM assessment has high sensitivity. The number of false-positive cases decreased with postconceptional age, as specificity increases in postterm period, for GM assessment. Therefore, both evaluation tools should be used in the detection of PTNB at a high risk of developing neurological abnormalities in the follow-up.

\section{Acknowledgments}

We are grateful to Elias Rodrigues de Paiva for the statistical analysis. The research was supported by a grant from FAPESP (Fundação de Amparo à Pesquisa do Estado de São Paulo, Brasil).

\section{References}

1. Volpe J]. Intracranial hemorrhage: germinal matrixintraventricular hemorrhage of the premature infant. In: Volpe JJ, editor. Neurology of the Newborn. 4th ed. Philadelphia: W. B. Saunders Co.; 2001. p. 428-93.

2. Volpe $]$ J. Brain injury in the premature infant. Clin Perinatol. 1997;24:257-87.

3. de Vries LS. Neurological assessment of the preterm infant. Acta Paediatr Scand. 1996;85:765-71.

4. Perlman JM. White matter injury in the preterm infant: an important determination of abnormal neurodevelopmental outcome. Early Hum Dev. 1998;53:99-120.

5. Leviton A, Paneth N. White matter damage in preterm newborns - an epidemiologic perspective. Early Hum Dev. 1990;24:1-22.

6. Pidcock FS, Graziani LJ, Stanley C, Mitchell DG, Merton D. Neurosonographic features of periventricular echodensities associated with cerebral palsy in preterm infants. J Pediatr. 1990;116:417-22.

7. Fowlie PW, Tarnow-Mordi WO, Gould CR, Strang D. Predicting outcome in very low birthweight infants using an objective measure of illness severity and cranial ultrasound scanning. Arch Dis Child Fetal Neonat Ed. 1998;78:175-8.

8. Roth SC, Baudin J, Pezzani-Golsmith M, Towsend J, Reynolds LOR, Stewart AL. Relationship between neurodevelopmental status of very preterm infants at one and eight years. Dev Med Child Neurol. 1994;36:1049-62.

9. Pinto-Martin J, Riolo S, Cnaan A, Holzman C, Susser MW, Paneth N. Cranial ultrasound prediction of nondisabling cerebral palsy at age two in a low birth weight population. Pediatrics. 1995;95:249-54.

10. Vohr B, Ment LR. Intraventricular hemorrhage in the preterm infant. Early Hum Dev. 1996;44:1-16.

11. de Vries JIP, Visser GHA, Prechtl HFR. Fetal motility in the first half of pregnancy. Clin Dev Med. 1984;94:46-64.

12. Prechtl HFR, Nolte R. Motor behavior of preterm infants. Clin Dev Med. 1984;94:79-92.

13. Cioni G, Prechtl HFR. Preterm and early post-term motor behavior in low-risk premature infants. Early Hum Dev. 1990;23:159-91.

14. Ferrari F, Cioni G, Prechtl HFR. Qualitative changes of general movements in preterm infants with brain lesions. Early Hum Dev. $1990 ; 23: 193-231$.

15. Prechtl HFR. State of the art of a new functional assessment of the young nervous system. An early predictor of cerebral palsy. Early Hum Dev. 1997;50:1-11.

16. Einspieler C, Prechtl HFR, Ferrari F, Cioni G, Bos AF. The qualitative assessment of general movements in preterm, term and young infants - review of the methodology. Early Hum Dev. 1997; 50:47-60.

17. Papile LA, Burstein J, Burstein R, Koffler $H$. Incidence and evolution of subependymal and intraventricular hemorrhage: a study of infants with birth weight less than $1500 \mathrm{~g}$. J Pediatr 1978;92:529-34.

18. Bos AF. Analysis of movement quality in preterm infants. Eur J Obstet Gynecol Reprod Biol. 1998;76:117-9.

19. Prechtl HFR, Einspieler C, Cioni G, Bos AF, Ferrari F, Sontheimer $D$. An early marker for neurological deficits after perinatal brain lesions. Lancet. 1997;349:1361-3. 
20. Bos AF, Martijn A, Okken A, Prechtl HFR. Quality of general movements in preterm infants with transient periventricular echodensities. Acta Paediatr Scand. 1998;87:328-35.

21. Prechtl HFR. Qualitative changes of spontaneous movements in fetus and preterm infant are a marker of neurological dysfunction. Early Hum Dev. 1990;23:151-8.

22. Geerdink JJ, Hopkins B. Qualitative changes in general movements and their prognostic value in preterm infants. Eur J Pediatr. 1993;152:362-7.

23. Albers S, Jorch G. Prognostic significance of spontaneous motility in very immature preterm infants under intensive care treatment. Biol Neonat. 1994;66:182-7.

24. Hadders-Algra M, Groothuis AMC. Quality of general movements in infancy is related to neurological dysfunction, ADHD, and aggressive behavior. Dev Med Child Neurol. 1999;41:381-91.

25. Bos AF, Van Loon AJ, Hadders-Algra M, Martijn A, Okken A, Prechtl HFR. Spontaneous motility in preterm, small-forgestational age infants II. Qualitative aspects. Early Hum Dev. 1997; 50:131-47.

26. Bos AF, Einspieler $C$, Prechtl HFR. Intrauterine growth retardation, general movements, and neurodevelopmental outcome: a review. Dev Med Child Neurol. 2001;43:61-8.

27. Shankaran S, Slovis TL, Bedard MP, Poland RL. Sonographic classification of intracranial hemorrhage. A prognostic indicator of mortality, morbidity, and short-term neurologic outcome. J Pediatr. 1982;100:469-75.
28. Stewart $A L$, Reynolds EO, Hope $P L$, Hamilton PA, Baudin J, Costello AM, et al. Probability of neurodevelopmental disorders estimated from ultrasound appearance of brains of very preterm infants. Dev Med Child Neurol. 1987;29:3-11.

29. Volpe JJ. Intraventricular hemorrhage and brain injury in the premature infant. Clin Perinatol. 1989;16:361-83.

30. Pinto-Martin JA, Whitaker AH, Feldman JF, Rossem RV, Paneth N. Relationship of cranial ultrasound abnormalities in lowbirthweight infants to motor or cognitive performance at 2, 6 and 9 years. Dev Med Child Neurol. 1999;41:826-33.

31. Ng PC, Dear PRF. The predictive value of a normal ultrasound scan in the preterm baby - a meta-analysis. Acta Paediatr Scand. 1990;79:286-91.

Corresponding author:

José Luiz Dias Gherpelli

Av. Albert Einstein, 627/1308

CEP 05651-901 - São Paulo, SP

Phone: (11) 3742.3362 / 3747.3308

Fax: (11) 3747.3508

E-mail: jldg@osite.com.br 